\title{
The Use of Evidence Based Research on Mathematics Textbooks to Increase Student Conceptual Understanding
}

\author{
Lisa O’Keeffe, John O’Donoghue \\ National Centre of Excellence in Mathematics \& Science Teaching \& Learning \\ (NCE-MSTL) \\ Department of Mathematics \& Statistics, University of Limerick
}

\begin{abstract}
Irish textbooks have only featured in a minor role in mathematic textbook analysis to date, the largest and most significant of such analyses is the TIMSS analysis [1] of which Irish textbooks were mentioned briefly. As part of her doctoral studies the author is investigating the impact of the current Irish Junior Cycle Mathematical Textbooks on student learning and in particular, student conceptual understanding. In conjunction with this aim the author is also identifying how improvements in mathematics textbooks can impact directly on student's conceptual understanding. This research, by means of textbook analysis, provides an insight into the standard of the current Junior Cycle mathematics textbooks while also identifying how improvements in these textbooks may impact on student conceptual understanding. The research presented here is the first of its kind specifically addressing the influence of mathematics textbooks in Ireland on teaching and student learning.
\end{abstract}

\section{Introduction}

Preliminary research by the author identified an over dominant influence of the mathematics textbook in Irish Junior Cycle classrooms (comparable with GSCE level). Despite the over reliance on these mathematics textbooks by teachers and students no research has been carried out to date in Ireland to validate their effectiveness for teaching or learning. This research, by means of textbook analysis, provides an insight into the standard of the current Junior Cycle mathematics textbooks while also identifying how improvements in these textbooks may impact on student conceptual understanding. The textbook analysis carried out by the author is primarily based on the work of Valverde et al[1] whose framework for text analysis comprises three main phases; Content, Structure and Expectation. However, the author found this to be insufficient for a complete analysis and thus added a 'Language' analysis element. This element is based on the work of Halliday [2] and Morgan [3].
A number of key findings which emerged from the textbook analysis were incorporated into a model chapter. Subsequently, this model chapter was implemented in a number of first year mathematics classrooms in order to identify the role of an improved textbook in student's conceptual understanding.

Conceptual development can be described as "learning that changes an existing conception" [4:1] It requires adjusting existing knowledge by shifting or reconstructing it in order to fundamentally change the existing concept to accept a new concept. Incorporating conceptual change into education can enhance a student's ability to overcome misconceptions and make them better prepared to deal with more difficult concepts. Vosniadou [5] emphasises that the easiest form of conceptual change is the addition of new information to existing knowledge. For example after learning the multiplication of natural numbers the conceptual change which would encourage development would be facing the problem of multiplication of fractions [5]. There is a need for conceptual development when new knowledge is incompatible with a student's existing knowledge. Students create presuppositions very early on in their learning which influence their beliefs. When they face new knowledge it may not all into line with their selfcreated beliefs so they need to create a synthetic model which combines the new theory with their individual beliefs and understandings [6].

Introducing conceptual development, the process where students are encouraged to question and reshape existing knowledge, would allow students to combine new and existing knowledge. This can be achieved by reshaping and modifying their existing synthetic models so that all knowledge (new and old) can assist in the formation of their understanding and beliefs, thus developing students' concepts of pattern recognition and abstract operations [7]. According to Merenluoto \& Lehtinen [8], conceptual development fails when students lack sufficient prior knowledge. When this occurs undetected student preconceptions very often create misconceptions. Preconceptions and misconceptions are difficult to change, meaning teachers can only help students advance in their learning by assisting them in creating and 
understanding new conceptions. In addition, there is a need for the affective, social and contextual factors which influence a classroom to be considered as they all contribute greatly to a student's conceptual development.

\section{Background to the 'Model Chapter'}

The framework for analysis applied in this study is primarily based on the work of TIMSS [1]. This framework comprises three main elements of analysis; Content, Structure and Expectation. The TIMSS framework was originally applied to 630 mathematics and science textbooks, while the study presented in this paper focuses entirely on mathematics textbooks. Having completed the analysis based on the TIMSS the author felt that a main area of the textbook had been excluded and thus included the element of 'Language'. The language element is based on the work of Halliday [2] and Morgan [3]. Halliday's framework for functional grammar analysis comprised three elements: Ideational Function, Interpersonal Function, and Textual Function. Morgan adapted this framework to apply it to students' own mathematical writings and in this study the framework is applied directly to mathematics textbooks.

On completion of the textbook analysis the main findings in conjunction with the literature findings were incorporated into a 'model chapter'. The topic for this model chapter emerged from research, from informal interviews and experiences by the author. This model chapter is dedicated to the topic of 'fraction addition' and is based not only on the textbook analysis findings but also on the frameworks outlined in table 1.

Table 1. Theoretical frameworks employed for the creation of the model chapter

\begin{tabular}{|c|c|}
\hline Theoretical Framework & Influence \& Siguificance \\
\hline J.C Syllabus (Ireland) & Content currently being covered at Junior Cycle level \\
\hline Project Math" (Ireland) & $\begin{array}{c}\text { Content to be covered when new curriculum is } \\
\text { implemented in September 2010 }\end{array}$ \\
\hline Currey et al* [9] & Adult Numeracy Network Framework \\
\hline Massachusetts Department of Education* [10] & Adult based Education Framework \\
\hline $\begin{array}{c}\text { Organisation for Economic Co-operation and } \\
\text { Development" }[11]\end{array}$ & Pisa Mathematical Cycle for Problem Solving \\
\hline
\end{tabular}

* $\quad$ Project Maths ${ }^{1}$, a new mathematics curriculum initiative was implemented nationwide in

1 Project Maths was implemented nationwide in September 2010 however the National Council for Curriculum and Assessment (in Ireland) have made a deliberate decision not to make any recommendations in regard to textbooks for Project
September 2010. One of the current aims of Project Math is to provide teaching and learning plans, teacher guides and student worksheet, online exemplification and a range of assessment materials. This new curriculum is based on five key strands:

* Statistics and Probability

* Geometry and Trigonometry

* Numbers

* Algebra

* Functions.

While 'fractions' are not explicitly stated as an individual strand, fraction manipulation is a central part of each. A proficiency in the manipulation of fractions and related operations is necessary for the successful execution of much of the Junior Cycle mathematics curriculum (both the old and new curriculum).

* $\quad$ The Adult Numeracy Network is an American initiative which created a framework for adult numeracy. The aim of this framework is to provide the mathematical skills and knowledge that adults need to be equipped with for their future lives. The ANN framework [9] which ties in with that of Benn [12] and Kaiser [13] provides a rational for the inclusion of fractions in adult numeracy education, while also highlighting some of the aspects of mathematics which they felt teachers need to consider prior to teaching topics such as the importance of teaching in context.

The Massachusetts Department of Education created ABE, an Adult Based Education curriculum framework in 2005. In this framework they outlined the underlying constraints required for numeracy eloquence, "Numerate behaviour involves managing a situation or solving a problem in a real context by responding to information about mathematical ideas that is represented in a range of ways and requires activation of a range of enabling knowledge, behaviours and processes" [10:7]. With this in mind they created a framework, whose core concepts are similar to those presented by the ANN framework.

The PISA framework [11], as outlined in figure 1, (based on that proposed in O.E.C.D., 2003) provides the final link for creating the framework for the fraction chapter. This particular framework is based on an assumption of mathematics as a human

Maths despite significant pressure from publishers and teachers. In order for Project Maths to succeed it should not be defined by the mathematics textbook as previous curriculum initiates have. 
activity, (RME and situated Cognition), and is referred to as mathematising.

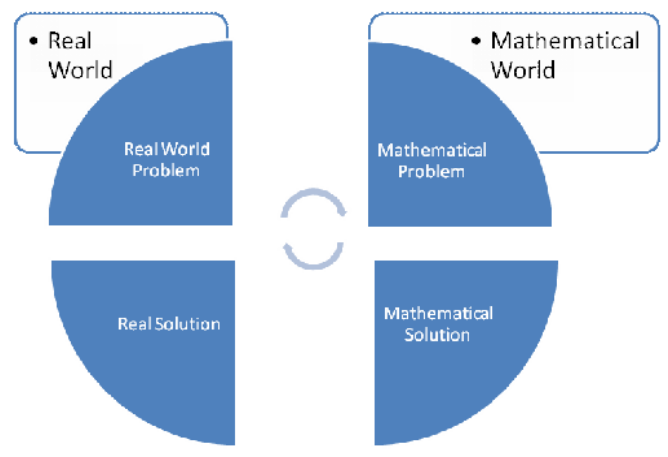

Figure 1. The PISA mathematical cycle

The selected frameworks (provided in Table 1) are based on the teaching and learning of numeracy as there is no specific framework currently in existence appropriate to the model chapter. The dictionary definition of numeracy is a 'mastery of the basic symbols and processes of arithmetic':
1. Numbers,
6. Simple Division,
2. Addition,
7. Simple Weights and
3. Subtraction, Measure,
4. Simple, 8. Money Counting
5. Multiplication, 9. Telling Time

These mathematical processes, as listed above, have many mathematical skills common to them, the ability to work with fractions being one. Fractions, while obviously an important component of any mathematics are "frequently mentioned as hard topic in school math" by both adults and children [9:36]. The four basic mathematical skills (numbered 2-5 above) are all relevant to and involved with fraction manipulation while numbers 6-9 rely heavily on fraction and decimal manipulation, for example when working with weight and measure.

Having considered the importance of the role of fractions in mathematics, specifically in Junior Cycle mathematics, the author chose to design a textbook chapter dedicated solely to fraction addition. The framework for the model chapter (Figure 2) is based upon the intentions of Project Maths, the Adult Numeracy Network (ANN) framework for teaching and learning numeracy [9] the Adult Based Education (ABE) framework [10] and the PISA Mathematical Cycle for Problem Solving [11]. At a first glance at this framework (Figure 2) it appears that fractions and solutions are feeding into the framework. The motivation behind this is based on the PISA Mathematical Cycle [11] which indicates that once a solution has been obtained it should feed back into the mathematical cycle and create more questions/problems. The reintroduction of solutions back into the cycle ensures a connection between the 'mathematical world' and the 'real world'.

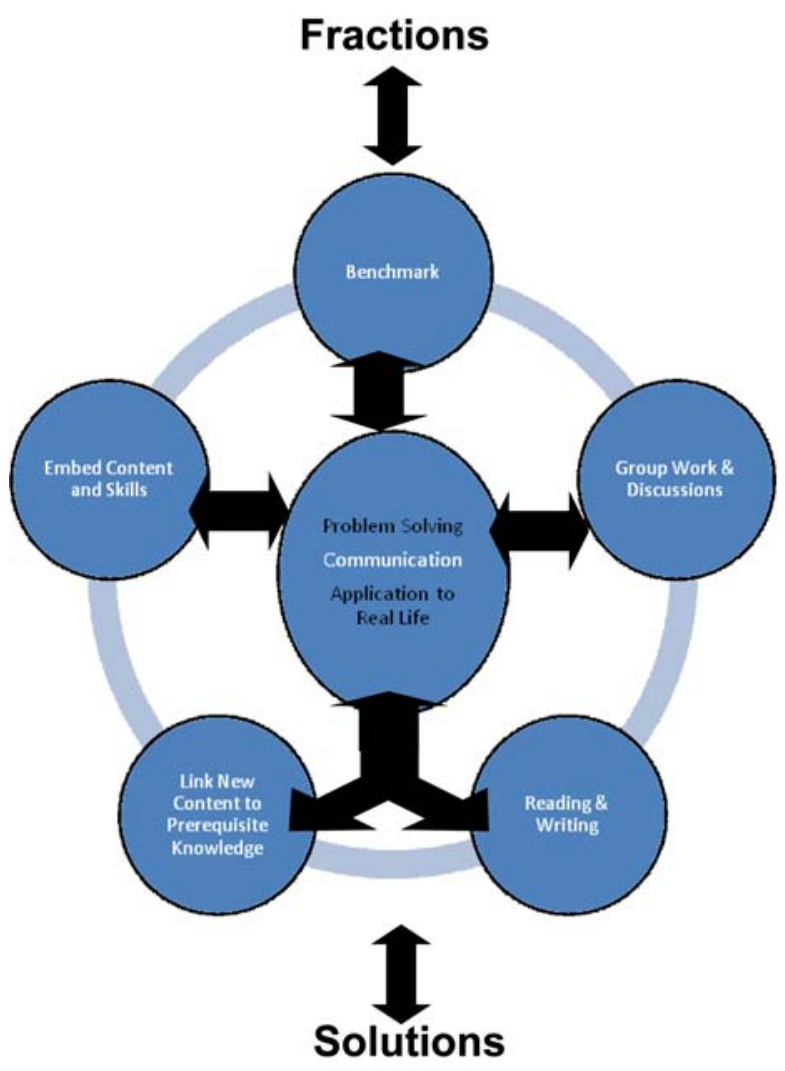

Figure 2. Framework for the Model Chapter

The inner cycle links directly with the Project Maths curriculum. One of the current aims of Project Math is to move the teaching focus towards a more problem based approach, intending to increase the presence and quality of applications and communication within the mathematics classroom. These three key areas (the inner circle) are the main focus of teaching and therefore the framework will direct the chapter to ensure that direct references are made to each of these approaches.

The outer circle dictates how to achieve the requirements of the inner circle. This outer circle is based on evidence from the ANN framework [9], the ABE framework [10] and the PISA Mathematical Cycle [11].

Benchmark refers to setting achievable yet challenging goals. While not explicitly mentioned in any of the aforementioned frameworks it is a common expectation which emerges for all.

Group work and discussions are vital for mathematical communication, ANN [9] emphases the role of group work and discussion in creating mathematical connections and for linking students' ideas. Similarly ABE [10] states that group work and discussion allow for student to student interaction. Thus helping students to voice, clarify and define 
their mathematical ideas while also assisting with the mathematising process, moving between the 'mathematical' and the 'real' world [9].

Reading and Writing is strongly connected with communication. Writing mathematics is common practice in many mathematical classrooms however it is usually limited to completing/working on exercises. Curry et al are referring to reading and writing when they speak about interdisciplinary i.e. mathematics is written and/or read only in the context of other subjects such as science. Writing one's mathematical ideas and beliefs should be an inclusive part of mathematical learning. Also, writing one's mathematical beliefs and concepts will assist with step 2 of the PISA Mathematical Cycle [11] organising one's thoughts according to mathematical concepts.

Linking new content to prerequisite knowledge will create the basis on which to start the PISA Mathematical Cycle [11] and will also assist with step 5: making sense of solutions. Students need to be able to connect new mathematics with what they already know in order to develop conceptually [4]. Some research has indicated that creating such links is vital to all mathematical learning [9]. Linking knowledge allows students to reason out problems and make decisions about how to approach the mathematics, all of which are essential in the ABE framework [10].

Embed Content and Skills is referred to in each of the existing frameworks. Teaching mathematics in context is vital in order to achieve the inner circle. Currey et al connect with the work of Benn [12] and Kaiser [13] when they discuss the relevance of teaching in context for student learning. According to Currey et al [9], teachers should be aware of the need for contextual mathematics and should directly apply the mathematics, where possible, to the lives of the students. Similarly, the PISA framework refers to mathematics as being likened to a human activity, which relies on content being embedded into the appropriate context (as in RME).

Having created the framework for the model chapter there are a number of key content and structural considerations which also need to be outlined. The model chapter content is based on a problem solving approach. This type of approach began featuring in mathematics education in the 1980's with both the American curriculum initiative, 'Agenda for Action' [14] and the British curriculum initiative [15], highlighting the significance of teaching with a problem based approach. A 'Problem Solving' approach to teaching provides students with a reason for doing the mathematics, an emphasis on strategies as opposed to rules and encourages the creative and developmental aspects of mathematics [16]. This 'Problem Solving' approach also aims to consider the students' conceptual development by ensuring the required prior knowledge is stated and options for revision are included, by encouraging and presenting active, co-operative, technology based and developmental learning [17]. Also the chapter will ensure that the material is learnable by considering the work of Hiebert et al, [18] whose research on how children learn mathematics identified three significant factors:

- Make connections to the Real World,

- Create links between rules and conceptual knowledge,

- Reflect on calculations and solutions.

According to Goetz \& Armbruster[19] discourse is easier to attain when it is collective. Robinson [20] provides a lot of research on the recommended textbook structure. His main findings (relevant to this study) focus on the importance of coherence and unity within a text. In order to ensure coherence it is vital to have a logical flow of content and the inclusion of summaries will assist with providing content unity.

Content within a text plays a vital role in student learning. Rivers [21] highlights the impact of content and content structure on students' motivation and comprehension. In order to maximise student motivation, this chapter will include historical and biography references, (where applicable), career information, applications to real life and photographs. The inclusion of colour and graphics will enhance comprehension, while encouraging the use of technical aids broadens the students' learning experience.

According to Noonan [22], illustrations can positively impact on student motivation but can be detrimental to students' mathematical reading if merely included in a text for decorative purposes. Dowling [23] has done much research on illustrations and diagrams. He recommends that diagrams be used in dual mode with the problems/exercises, that they should be simple and easy to read, coloured and realistic (real if possible).

The presence and organisation of titles throughout a textbook, or in this case a chapter, refers directly to the language applied. This chapter is designed for first year secondary school mathematics students therefore the school mathematical register is most applicable. According to Balas [24], how one reads mathematics has a significant impact on how one learns mathematics. As mathematics is a language in its own right this chapter will encourage the reading of mathematics. In order to maximise student learning outcomes the findings of Noonan [22]:

- In order to minimise the difficulties associated with words of dual meaning (mathematical meaning is different to the ordinary English meaning) vocabulary lists will be included.

- Noonan [22] made reference to the impact of the syntax of a mathematical text and states that 
short sentences cause less confusion to reading than long sentences.

- Diagrams, while they have major motivational advantages, can disrupt reading if not relevant.

- Symbols cannot be 'sounded out' like words so therefore a list of symbols and their meanings will also be included.

- Rhetorical questions serve only to confuse students therefore will be omitted.

- The page layout should not be cluttered, should be appealing and bright.

\section{Methodology}

The importance of fractions and their role in numeracy and mathematics in general is unchallenged. The above frameworks, though not explicitly devoted to the teaching of fractions, have highlighted the significance and indeed necessity of a good knowledge base in fraction addition and hence have been adapted, combined and modified to enable the author to create a framework suitable for the teaching of fractions (Figure 2). This framework in conjunction with the key design features (findings from the textbook analysis in conjunction with the findings from the literature) are used to create and design the model chapter.

The author created a model chapter which is centered on the topic of adding fractions. Fractions were selected based on the author's own experiences as a teacher, from informal feedback from students of all ages and a number of studies which highlight the difficulties that students' experience with fraction manipulation. The design for this model chapter evolved from a combination of four well established relevant frameworks, Project Maths and the Junior Cycle curriculum, Adult Numeracy Network [9] Adult Based Education [10] and the Pisa Mathematical Cycle [11]. Following a pilot, review and amendment phase this model chapter was implemented in a number of first year mathematics classrooms. Nine classes from three different secondary schools were involved in this study. Within each school there were two test groups and one control group. The test groups replaced their original textbook with the model chapter for the fraction addition section of their curriculum. The original textbook remained in one classroom in each school and this class group acted as the control group. A total of nine class groups were involved in this study totalling 195 students. All 195 students were subject to pre and post testing in both the test and control group.

The model chapter was used in conjunction with a two tier diagnostic test to ascertain its effectiveness in enhancing student conceptual development and also a mathematics anxiety rating scale. This two-tier diagnostic test was based on the work of Treagust [25], while the mathematics anxiety rating scale employed in this research study was the RMARS (Revised Mathematics Anxiety Rating Scale), a mathematics anxiety measure designed and created by Plake \& Parker [26]. Prior to begin this intervention each student completed a two-tier diagnostic test and an anxiety survey. The model chapter was then used by the test groups for the duration of fraction addition while the control groups continued as normal. After completion of the topic fraction addition all students were again subjected to the same two-tier diagnostic test and anxiety survey.

\section{Main Findings}

\subsection{Textbook Analysis Findings}

An outline of the main findings from the textbook analysis is presented here to situate the findings from the model chapter intervention.

The three most commonly used textbook series (each containing two textbooks giving a total of six textbooks) in Ireland were identified and subjected to detailed analysis by the author; each of these textbook series was also used in a control group within the final phase of this research.

The textbook analysis identified that all of the textbooks were particularly weak in terms of student motivation and comprehension. One of the textbook series does however emerge as being better than the other two; this will be referred to as 'textbook series 3'. According to River's [21] textbooks should offer innovative resources. The Rivers matrix identifies key textbook features which impact directly on comprehension and motivation. However, none of the textbook series examined were innovative in this sense. With regard to problem solving, less than one quarter of all exercises present in all of the textbooks could be classified as problems, with the highest presence of problems evident in 'textbook series 3'. It is worth noting that Dowling [23] states that excessive and unnecessary use of colour can hinder comprehension. Each textbook series does take this into consideration but colour consistencies across the textbooks are minimal and while there is no shortage of graphics throughout any of the textbooks, the presence of real life graphics is extremely low with four of the textbooks having no real life graphics. The main emphasis which came across in all textbooks examined was 'Proficiency and Logic'; all books were focused on being able to complete a number of questions. The textbook analysis also determined that within these textbooks the focus is on the intellect, understanding is not given the same importance as procedure and method throughout each of the textbooks ([21], [1], and [27]).

The language analysis also indentified a number of problem areas within the textbook series, each has a high presence of passive sentences, an overuse of 
the pronoun 'we' and a high frequency of specialist vocabulary and use of symbolism, all of which combine to confuse students. The language analysis also discovered that the theme of textbook series 3 differs from the other textbook series in that it has a narrative theme, however all textbook series have little evidence of an emphasis on logical reasoning.

\section{2 Model Chapter Intervention Findings}

The model chapter was piloted, amended and tested within three secondary schools. Each school was using one of the three textbook series indentified at the beginning of the study. Three first year (lower secondary school) mathematics classes within these schools were involved in the study and one of these classes acted as a control group. The test group replaced their usual textbook with the model chapter and the control group continued as normal. Both groups were subject to pre and post testing.

The data collected from each school is analysed independently, as the ANOVA tests found there are statistically significant differences between each school therefore in order to ensure valid results it is necessary to analyse the data on a school by school basis. Paired t-tests are utilised to analyse the data from each school in order to identify the changes between pre and post tests for each class independently. The test groups within each school exhibited statistically significant increases $(p<0.05)$ in their conceptual development following the teaching period with the model chapter. In contrast to this only one of the control groups demonstrated statistically significant changes in their conceptual development. The control group (in School 1) who exhibit a statistically significant increase in conceptual development are using TBS C. The findings from the textbook analysis of this study suggest that TBS $\mathrm{C}$ exhibits a greater consideration for who its intended reader is.

Independent t-tests are then conducted to compare the increases in conceptual development between test and control groups. The findings from the independent t-tests indicate that some test groups did statistically better than the control groups but some did not. This could be due to the many external factors which are beyond the control of this study e.g. teacher, classroom environment etc.

The anxiety levels of these students were also subject to pre and post testing using Revised Mathematics Anxiety Rating Scale (RMARS) [12]. The decrease in anxiety is statistically significant for all test groups and again the control group in school 3.

\section{Discussion}

Despite the fact that O'Keeffe [28] noted that over $50 \%$ of teachers in her study rely on only one textbook for classroom planning and teaching (textbook series 1), it appears that textbook series 3 exhibits a greater understanding for who its intended reader is. This paper is not suggesting that this textbook is the most beneficial for student learning, but rather it is the best available in the current situation. The author is highlighting the need for this type of research on textbooks to be conducted and most importantly applied. What this research is advocating for is to increase the standards of mathematics textbooks in order to enhance the teaching and learning at Junior Cycle (lower secondary school).

The aim of the model chapter is to show that if changes were made to mathematics textbooks then we could hope to see changes within student's conceptual development and understanding. The pre and post testing allowed the author to identify the average baseline scores for both the control and test group. Independent t-tests were applied which showed that there is no statistically significant difference between the baseline scores for the test and control group, which means that the students in the test and control groups are at the same level prior to this study. The three week intervention then involved the model chapter replacing the original textbook within the test classes. All of the test groups indicated a statistically significant increase in their conceptual understanding. Only one of the control groups indicated a significant change in their conceptual understanding. These statistically significant differences indicate that something within the three week intervention is causing a bigger increase in student's conceptual understanding within the test groups. Like any study there are a number of factors which may influence students learning however the author did not interfere in anyway other than to introduce a textbook change. No teaching suggestions or recommendations were provided outside of what was in the teaching material provided. These results would indicate that positive changes in student learning have occurred with the introduction of an evidence based mathematics textbook (chapter). This would suggest that if effective changes were applied to mathematics textbooks and evidence based mathematics textbooks were designed and created positive increases in student conceptual development could be expected.

\section{Conclusion}

Almost $50 \%$ of teachers currently teaching mathematics at second level in Ireland do not have a mathematics specific qualification [29] and the majority of qualified mathematics teachers in second level schools are teaching at Leaving Certificate level (upper secondary school). This indicates that Junior Cycle mathematics is poorly populated with qualified mathematics teachers and this reality 
underlines the need for improved textbooks. Unqualified teachers may lack sufficient subject matter knowledge and reliance on substandard textbooks may be harmful to students learning experience. Howson [30] suggests that the role of the textbook is the most dominant and powerful in mathematics education; he believes that it is associated with almost all aspects of teaching and learning mathematics.

In order to facilitate and complement changes in the Irish mathematics curricula at both Junior and Senior Cycle it is then necessary to review the available textbooks. This paper highlights the failure of the current Junior Cycle Mathematics textbooks to motivate pupils, or to provide for the comprehension and processing of the information provided, while also highlighting the role improved textbooks can play in student learning. Project Math will bring change into Irish classrooms from September 2010, improved textbooks can help facilitate such change and enhance pupil learning. However it is important that any textbook changes are based on relevant literature and findings to ensure effective changes are implemented.

\section{References}

[1] Valverde, G., Bianchi, L., Wolfe, R., Schmidt, W. and Houang, R. (2002), "According to the Book: Using the TIMSS to Investigate the Translation of Policy into Practice through the World of Textbooks", Kluwer Academic Publishers, London.

[2] Halliday, M. (1973), "Explorations in the Functions of Language”, Edward Arnold, London.

[3] Morgan, C. (2004), “Writing Mathematically: The Discourse of Investigation”, Falmer Press, London.

[4] Orey, M. (2001), "Emerging perspectives on learning, teaching and technology", Available online at http://projects.coe.uga.edu/epltt/index.php?title=Conceptua lChange [accessed 10/10/07].

[5] Vosniadou, S. (1994), "Capturing and modeling the process of conceptual change”, Learning and Instruction, $4(1), 45-69$.

[6] Biza, I., A. Souyoul, and T. Zachariades (2005), "Conceptual change in advanced mathematical thinking", paper presented at the Fourth Congress of European Society for Research in Mathematics Education, Saint Felix de Gu'ixols, Spain, pg 1727-1736.

[7] Snowman, J. and R. Biehler (2006), "Psychology Applied to Teaching”, Houghton Mifflin Company, Boston.

[8] Merenluoto, K. and E. Lehtinen (2004), “Number concept and conceptual change: towards a systemic model of the processes of change", Learning and Instruction, 14, 519-534.
[9] Curry, D., Schmitt, M., and Waldron, S. (1996), “A framework for adult numeracy standards: The mathematical skills and abilities adults need to be equipped for the future", The Adult Numeracy Practitioners Network System Reform Planning Project, July 2006

[10] M.D.E. (2005), "Massachusetts adult basic education curriculum framework for mathematics and numeracy", Adult and Community Learning Services, October, 2005

[11] O.E.C.D. (2006), "Assessing scientific, reading and mathematical literacy a frame-work for Pisa 2006”, Technical report, Paris, OECD.

[12] Benn, R. (1996), “Adults Count Too: Mathematics for Empowerment”, National Institute of Adult Continuing Education, Leicester

[13] Kaiser, G. (2005), “Mathematical modelling in school examples and experiences", paper presented at the Fourth Congress of European Society for Research in Mathematics Education, Saint Felix de Gu'ixols, Spain, pg 17- 21

[14] NCTM (1980), “An Agenda for Action: Recommendations for School Mathematics of the 1980s", National Council of Teachers of Mathematics: Reston, Virginia.

[15] Cockroft, D. W. (1982), "Mathematics Counts: Report of the Committee of Inquiry into the Teaching of Mathematics in schools”, Her Majesty's Stationary Office: London

[16] Neyland, J. (1995), "Mathematics Education: A Handbook for Teachers", The Wellington College of Education: Wellington.

[17] Hirsch, C. (1992), "Curriculum and Evaluation Standards for School Mathematics Agenda Series, Grades 9-12: A Core Curriculum: Making Mathematics Count for Everyone”, National Council of Teachers of Mathematics: Reston, Virginia.

[18] Hiebert, J., R. Gallimore, H. Garnier, K. Givvin, J. Jacobs, H. Hollingsworth, A. Chui, D. Wearne, M. Smith, N. Kersting, A. Manaster, E. Tseng, W. Etterbeck, C. Manaster, P. Gonzales, and J. Stigler (2003, March), "Teaching Mathematics in seven countries: Results from the TIMSS 1999 Video Study", National Centre for Education Statistics: U.S. Department of Education: Washington, DC.

[19] Goetz, E. and B. Armbruster (1980), "Psychological correlates of text structure". In R. Spiro, B. Bruce, and W. Brewer (Eds.), Theoretical Issues in Reading Comprehension: Perspectives from Cognitive Psychology, Artificial Intelligence, Linguistics, and Education, pp. 201220, Erlbaum: Jew Jersey.

[20] Robinson, J. (1981), "Research in Science Education: New Questions, New Directions", Clearinghouse for Science, Mathematics, and Environmental Education, ERIC, ED 209075, Ohio. 
[21] Rivers, J. (1990), “Contextual Analysis of Problems in Algebra 1 Textbooks", University of South Carolina, presented at the annual meeting of the American Educational Research Association, Boston: Massachusetts.

[22] Noonan, J. (1990), "Readability problems presented by mathematics texts", Early Child Development and Care, 54, 57-81.

[23] Dowling, P. (1996), “A Sociological Analysis of School Mathematics Texts", Educational Studies in Mathematics, 31(4): 389-485.

[24] Balas, A. (2000), "The mathematics and reading connection", Available online at www.ericdigests.org/2000-1/math.html-16k [accessed: 16/11/07].

[25] Treagust, D. F. (1988), "Development and use of diagnostic tests to evaluate students misconceptions in science”, Journal of Biological Education, 10 (2), 159169.

[26] Plake, B. and C. Parker (1982), "The development and validation of a revised version of the mathematics anxiety rating scale", Educational and Psychological Measurement, 42, 551-557.

[27] O’Keeffe, L \& J. O’Donoghue, 2009 “Assessing the effect of mathematics textbook content structure on student comprehension and motivation" in Corcoran, D., Dooley, T., Close, S. and Ward, R., eds., Third National Conference on Research in Mathematics Education, St. Patrick’s College of Education, Dublin.

[28] O’Keeffe, L. (2007), “An Analysis of the Junior Cycle Mathematical Textbooks", unpublished final year dissertation, University of Limerick, (submitted March, 2007).

[29] Ni Ríordáin, M \& A. Hannigan (2009), “Out-of-Field Teaching in Post primary Mathematics Education", Research Report, NCE-MSTL, University of Limerick.

[30] Howson, G. (1995), "Mathematics Textbooks: A Comparative Study of Grade 8 Texts", Pacific Education Press: Vancouver. 